\title{
A Method of Control for the Ventilation and Recording of: Temperature, Relative Humidity and Light in Beef Traceability
}

\author{
Andrea Simoni ${ }^{\S}$, Ferruccio Giametta ${ }^{\S}$ and Giovanna La Fianza ${ }^{*}$,
}

S.A.V.A. Department-University of Molise, via De Sanctis, 86100 Campobasso, Italy

\begin{abstract}
Aim oft the present study is to implement a method of ventilation control to be applied to two Molise-based beef cattle breeding farms.

The study focuses on the detection of those parameters (temperature, relative humidity and light) deemed to be crucial for the animals' life conditions in terms of both microenvironment(s) and "animal well being".

Two abacuses have been worked out to calculate the minimum ventilation rate required as well as the number of total air changes needed at one hour intervals as a function of the $\mathrm{CO}_{2}$ levels to be maintained in the cowsheds.

Such a system, in a point of view of beef traceability, also demonstrated to be useful for a very first assessment of the meat obtained.
\end{abstract}

\section{INTRODUCTION}

The present study focuses on a monitoring system relying on some parameters used to traced out particular cowshed conditions. The animal's welfare depends on: a) appropriate design of livestock houses; b) accurate control by the farmer of indoor temperature, relative humidity, ventilation and light. A good ventilation is fundamental to guarantee animal's welfare. The method of a climatization control may vary according to the season. During hot seasons the ventilation rate is expected to eliminate the heat produced in the cowhouse whereas during cold seasons the minimum ventilation rate is expected to be sufficient to reduce, in addition to the water vapour produced by animals, the amount of carbon dioxide generated in the cowshed [1]. In particular the summertime ventilation must be i) greater than that required during winter and ii) sufficient to eliminate $\mathrm{CO}_{2}$. The control of the above two distinct ventilation rates by previous parameters is very useful both to calculate the minimum rate of ventilation and to dimension the system used for air changes $[2,3]$. Carbon dioxide is used as an element of control, because it's produced by the animals and, in part, also by the biological reactions taking place in the litter. Its level is quite constant outdoor $(350 \div 380 \mathrm{ppm})$ instead of the amount of water vapour outdoor which can vary a lot even during the same day. The data collected are then re-processed to trace out the environmental conditions of cowsheds. The values of temperature and humidity are utilized to calculate THI (temperature and humidity index), that allows to relate the environmental conditions to the likelihood of economic damage linked to heat stress [4]. THI values are then utilized to assess LSI (livestock safety index), that links environmental

*Address correspondence to this author at the S.A.V.A. DepartmentUniversity of Molise, via De Sanctis, 86100 Campobasso, Italy;

E-mail: lafianza@unimol.it

${ }^{\S}$ The authors have contributed to the same extent to the present study conditions to livestock physiological conditions [5]. Based on carbon dioxide monitoring, a calculation abacus of the ventilation rate related to the size of the animal's house as well as to both species and size of the animals breed has to be devised. The value assessed in this manner can be immediately correlated to the rate of ventilation present in the animal house thus allowing for the assessment of the quality of the breeding conditions under study. The determination of the light conditions in the cowsheds permits a good evaluation of the work environment and may allow these data to improve breeding techniques [6]. These data may be useful for future consumers in terms of beef traceability [7, 8].

\section{MATERIALS AND METHODS}

The two animal houses under investigation rely on the different breeding techniques:

- A: beef cows pens;

- B: stall housing.

Each kind of breeding technique adopted calls for a specific shape of the building devoted to host the animals. Building A is mainly open, whereas building B is a closed facility. The parameters measured were as follows:

$$
\begin{aligned}
& \text { - temperature }\left({ }^{\circ} \mathrm{C}\right) \\
& \text { - relative humidity } \\
& \text { - } \mathrm{CO}_{2} \text { (ppm) } \\
& \text { - Light intensity (lux). }
\end{aligned}
$$

The tools used to collect data were: a HOBO data logger used to measure and to record the previous parameters and to collect the values of $\mathrm{CO}_{2}$ with an upper limit of 2,500 ppm. The assessment of the amount of $\mathrm{CO}_{2}$ in the air was made with a specific tool, Telaire with an IR sensor, a device allowing for measurements with an upper limit of 10,000 ppm but with a recording outlet limited to $4,000 \mathrm{ppm}$. Data were recorded at one-hour intervals. The tools were placed inside the two cowsheds. During the experimentation period cow- 
shed A hosted 20 bullocks with an average weight of $350 \mathrm{~kg}$ each, 40 milk cows with an average weight of about $600 \mathrm{~kg}$ each and 20 heifers of about $400 \mathrm{~kg} /$ animal. Cowshed B contained 12 bullocks with an average weight of $550 \mathrm{~kg}$ and 18 calves with an average weight of $300 \mathrm{~kg} /$ animal. Using the parameters related to the animal total heat production, based on species and weight of the animals [1], the mean total heat produced in the two cowsheds were calculated: $A=80,100$ $\mathrm{W} ; \mathrm{B}=21,850 \mathrm{~W}$. The sizes of cowshed A were: $34 \times 20 \times 5.12$ $\mathrm{m}$; volume: $3,485 \mathrm{~m}^{3}$. Cowshed A ventilation system was defined as "natural". Cowshed B sizes were: 25x9x4 m; volume: around $900 \mathrm{~m}^{3}$. Also in B ventilation was classified as natural.

The temperature and relative humidity data recorded have been analyzed calculating the temperature index and the THI (Temperature Humidity Index).

The adopted calculation formula [5] is:

$$
\mathrm{THI}=(1,8 \cdot \mathrm{T}+32)-(0,55-(0,55 \cdot \mathrm{UR} / \mathbf{1 0 0})) \cdot((1,8 \cdot \mathrm{T}+32)-58)
$$

dove:

$\mathrm{T}=$ temperatura ambiente rilevata in ${ }^{\circ} \mathrm{C}$;

$\mathrm{UR}=$ umidità relativa in valore $\%$

To calculate ventilation rate a formula indicated in the 4th CIGR Report of the Working Group on Climatization of Animal Houses [3] was utilized which includes calculation per hpu $\left(1 \mathrm{hpu}=1,000 \mathrm{~W}\right.$ of total heat produced at $\left.20^{\circ} \mathrm{C}\right)$. Assuming as an average parameter $0,185 \mathrm{~m}^{3} / \mathrm{h}$ of $\mathrm{CO}_{2}$ produced for hpu and assuming the typical data related to the herds housed in each one of the two cowsheds, the abacuses for the situations under study were obtained, calculating the equation (1) and including the amount of $\mathrm{CO}_{2}$ measurable inside the animal house as an independent variable:

$$
Q v(h p u)=\frac{0.185}{\left(C O_{2-\text { indoor }}-C O_{2-\text { otdoor }}\right) \cdot 10^{-6}}
$$

where:

Qv $(\mathrm{hpu})=$ rate of ventilation in $\mathrm{m}^{3} / \mathrm{h}$ per $1000 \mathrm{~W}$ of total heat produced by the animal present in the animal house ( 1 hpu);

$\mathrm{CO}_{2 \text {-indoor }}=$ ppm of $\mathrm{CO}_{2}$ present in the air inside the animal house;

$$
\mathrm{CO}_{2 \text {-outdoor }}=\text { ppm of } \mathrm{CO}_{2} \text { present outdoor. }
$$

The formula that generates the abacus of cowshed (A) is as follows:

$$
Q v=\frac{0.185 \cdot 80.1 \cdot 10^{6}}{\left(C O_{2-\text { indoor }}-C O_{2-\text { outdoor }}\right)}
$$

The formula that generates the abacus of cowshed (B) is as follows:

$$
Q v=\frac{0.185 \cdot 21.85 \cdot 10^{6}}{\left(C O_{2-\text { indoor }}-C O_{2-\text { outdoor }}\right)}
$$

\section{RESULTS}

After a first processing of the temperature and relative humidity data the THI was calculated to identify the pattern of these parameters during the period under study (JuneSeptember 2005). This value is function both of the temperature and the relative humidity and it's a useful tool to define whether alert thresholds have been exceeded (beyond which economic damage due to heat stress is likely to occur: [5]. From the THI pattern in the two cowsheds (Fig. 1) it could be deduced that the minimum values recorded in stall housing conditions (B). (72-74) during summer have a mean value higher than those measured in the beef cow pens (A) (65-70).

In particular, during summer stall housing conditions (B) show minimum daily values of THI always higher than those recorded in the cow pens (A). In particular, these values exceeded the threshold level forseen for this kind of animal houses (B). In the study period the amount of $\mathrm{CO}_{2}$ in the cowsheds was monitored to assess the efficiency of the ventilation system adopted. The graph in Fig. (2) shows that the organization adopted during winter implies a remarkable amount of $\mathrm{CO}_{2}$ in this period in $\mathrm{B}$. This indicates that the rate of ventilation is not sufficient to match ideal conditions of breeding. The series of data assessed allow to analyze and evaluate their trend.

Therefore an abacus was worked out which allows to calculate the minimum ventilation rate (winter), and the relevant number of total air changes to be made at one-hour intervals as a function of the level of $\mathrm{CO}_{2}$ that has to be kept in the cowshed. Analyzing the data collected in the two animal houses in December 2005 (graph in Fig. 2), it can be observed that in stall housing conditions (B) the level of about $2,500 \mathrm{ppm}$ of $\mathrm{CO}_{2}$, is the highest data recordable by the data logger utilized. This value is reached during the night and in the period of the highest metabolic activity of the animals. This may indicate that in real conditions the value of 3,000 ppm, (a limit indicated, albeit only advised as the maximum allowed) [2] could be easily exceeded. Under the abacus of cowshed B 2,500 ppm correspond to a ventilation flow of about $1,900 \mathrm{~m}^{3} / \mathrm{h}$, about 2.1 total air changes/hour. Analizyng the pattern of the $\mathrm{CO}_{2}$ parameter in cowshed $\mathrm{A}$ it can be observed that the maximum values are of about 1,200 ppm. The assessment of the system adopted to guarantee an appropriate ventilation flow was made utilizing, also in this case, the abacus related to the same cowshed (graph in Fig. 3).

At a value of 1,200 on the $\mathrm{x}$-axis corresponds an actual ventilation flow of about $18,000 \mathrm{~m}^{3} / \mathrm{h}$, this volume gives a total of 5.2 air changes/hour, a value by far higher than that calculated for cowshed B. (Fig. 4). Usually the threshold level of $\mathrm{CO}_{2}$, beyond which the environments where the humans live must be ventilated, is of about 700 ppm higher the amount of the same gas present outdoor (ASHRAE Standard 62-1989).

These values are lower than those advised by the regulations in force in some countries regarding animal's welfare. But if the animals hosted in cowsheds are accustomed to live in human environmental conditions, how can we just foresee different optimal levels of $\mathrm{CO}_{2}$ for the two "species" in question? No doubt, we are not able to communicate with animals and know their impressions, but, from an ethological point of view it seems non appropriate to breed animals in places whose some fundamental parameters are incompatible 


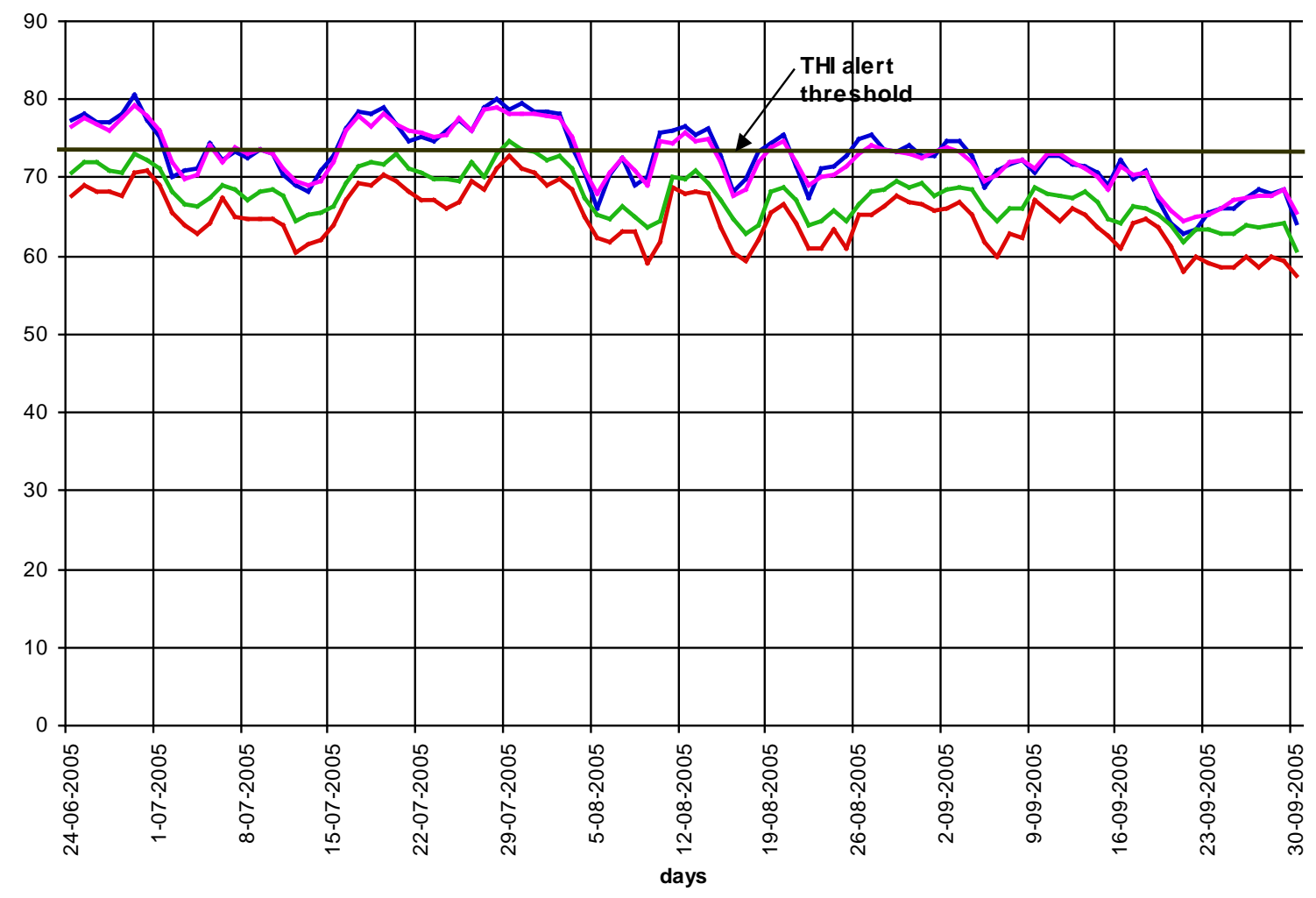

$\Longrightarrow \max .(A)=\max .(B)=\min .(A)=\min .(B)$

Fig. (1). Pattern of the minimum and maximum value of THI $x$ in A and B. Minimum values exceed THI alert threshold in B.

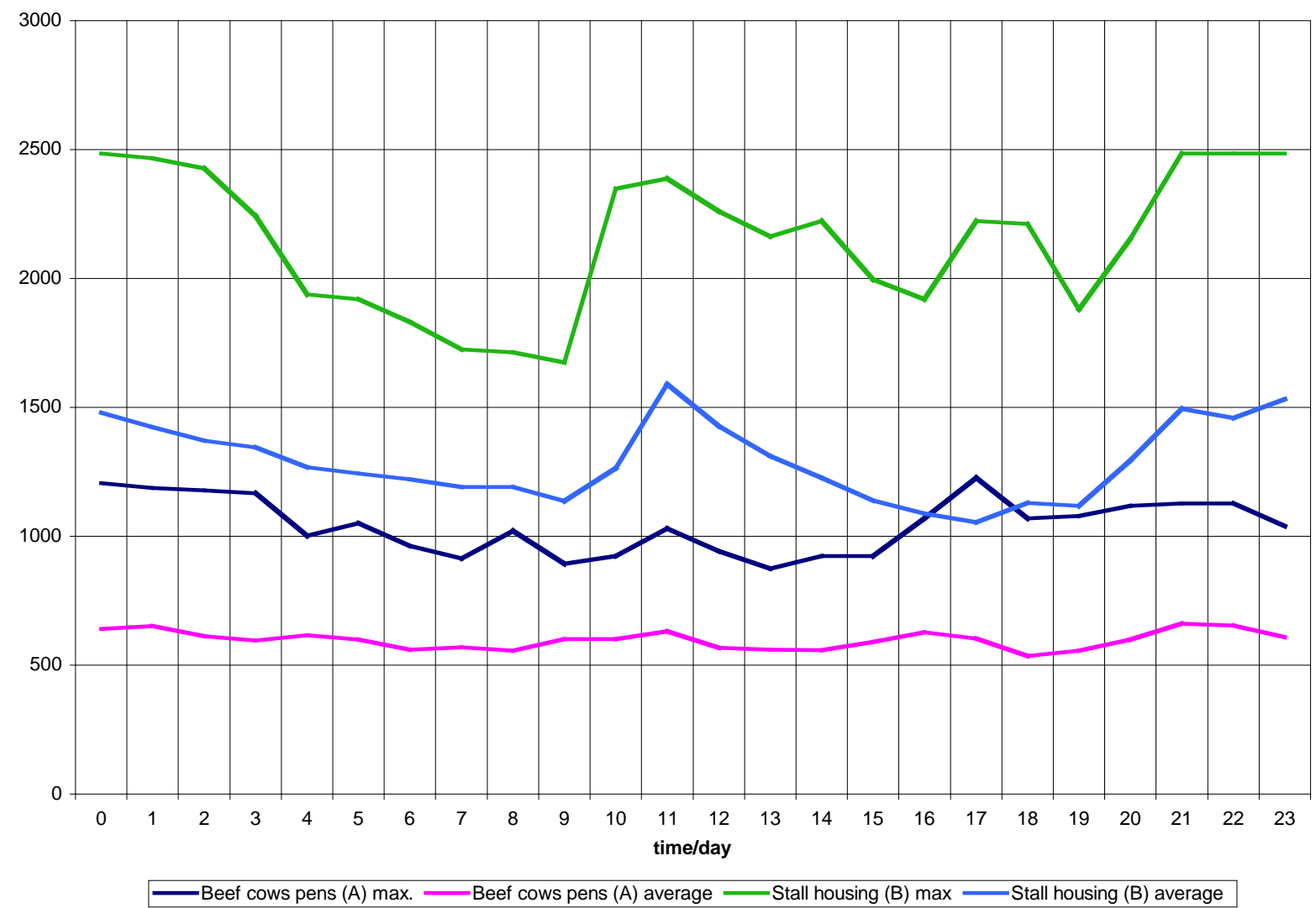

Fig. (2). Maximum and average amount of $\mathrm{CO}_{2}(\mathrm{ppm})$ present in the animal houses in the month of the December (2005). 


\section{Abacus beef cows pens (A)}

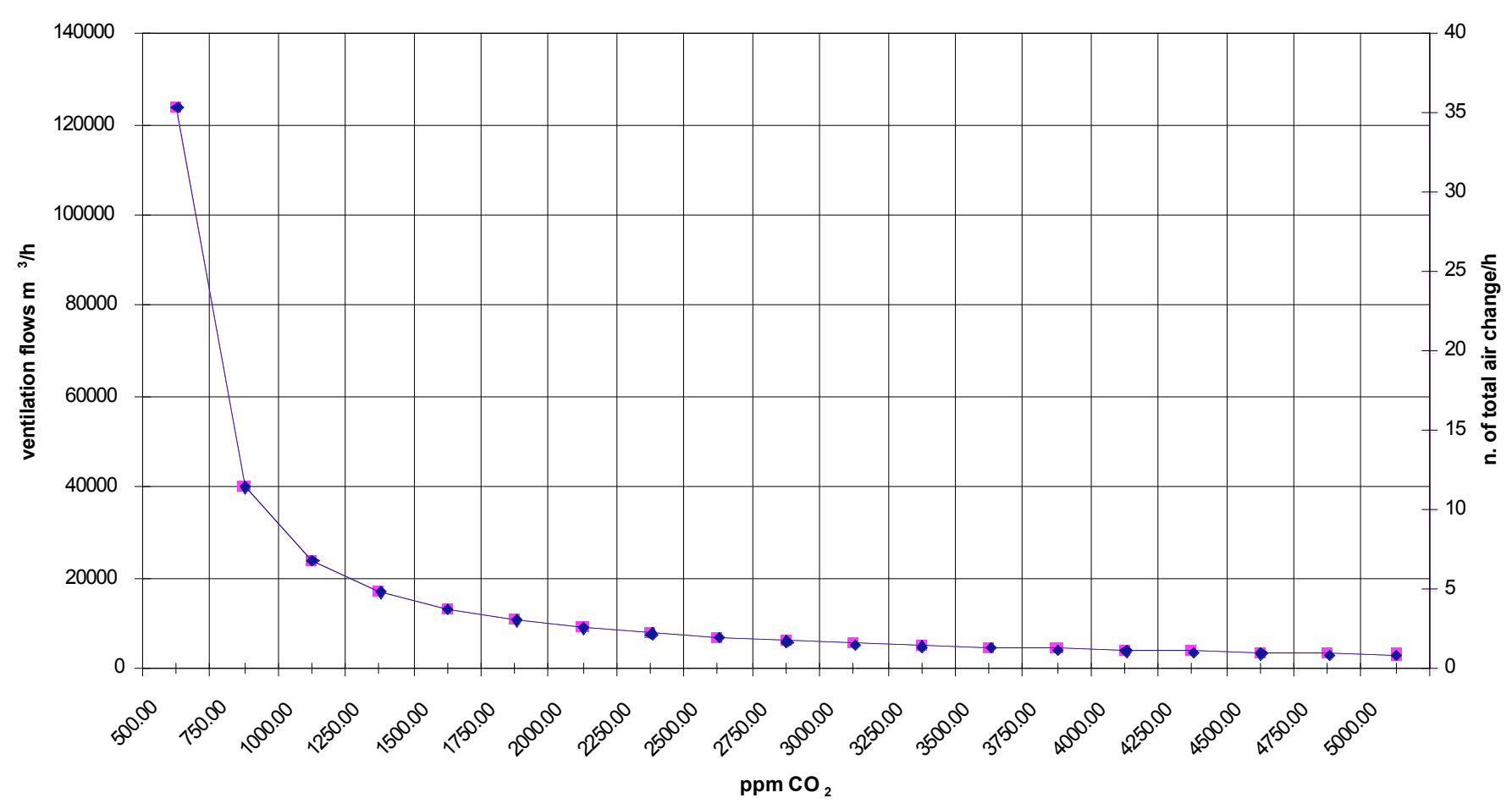

Fig. (3). Abacus used to calculate minimum ventilation flow $\left(\mathrm{m}^{3} / \mathrm{h}\right)$ and no. of total air charnge/h in cowshed (A).

Abacus stall housing (B)

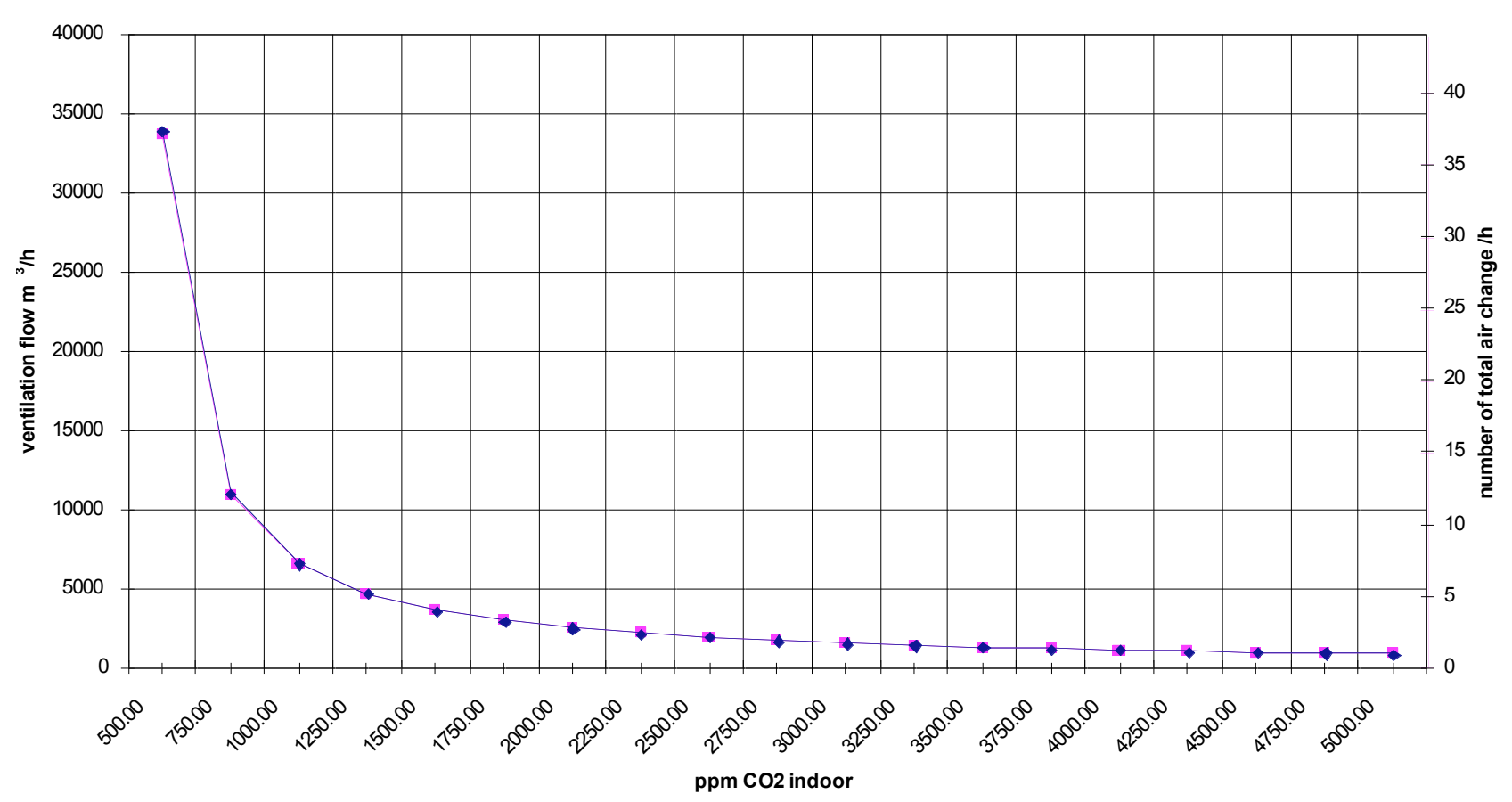

Fig. (4). Abacus used to calculate minimum ventilation flow $\left(\mathrm{m}^{3} / \mathrm{h}\right)$ and no. of total air charnge/h in cowshed (B).

with human needs. The analyzed data in A show a level of $\mathrm{CO}_{2}$ compatible with the working operators. The light present in the two cowsheds was also measured. For sake of semplicity we present data concerning the months of November and December 2005. The graph in Fig. (5) shows the values recorded and processed as hourly averages.
The quantity of light present in the cowsheds enables us to state that the two kinds of animal houses in question did differ also in terms of this additional parameter. However it emerges that during daytime hours the cowsheds have a poor lighting. Poor lighting has a negative impact on the work of operators and breeding operations turn out to be difficult to 


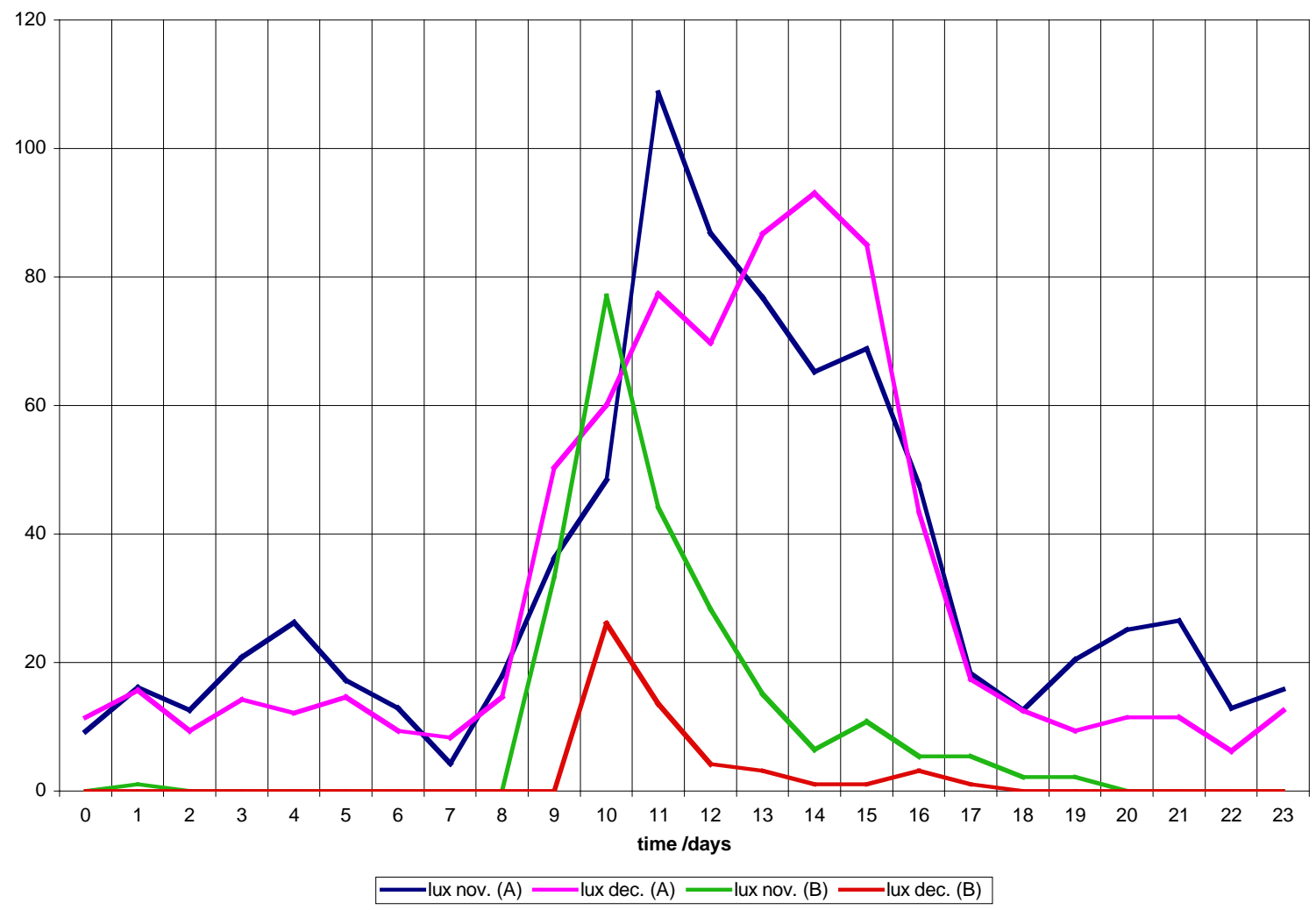

Fig. (5). Pattern of the average lighting registered in the cowsheds under investigation in November and December, 2005.

perform. The optimal lighting level in regular cowsheds should rely on a minimum of 50 lux in rest areas [6].

\section{CONCLUSIONS}

The work carried out give us the possibility to get information related to the trend of some parameters helping to determinate the assess of animals breeding conditions, The data recorded showed different parameters (THI and $\mathrm{CO}_{2}$ ) between the two housing considered and is much worse in stall housing. In particular during summer THI minimum values exceed also the alert threshold foreseen, whereas the amount of $\mathrm{CO}_{2}$ remains rather high also during winter. The two abacuses allowed to calculate the minimum ventilation rate required as well as the number of total air changes made at one hour intervals. Moreover the ventilation rate $\left(18,000 \mathrm{~m}^{3} / \mathrm{h}\right)$ in $\mathrm{A}$ is higher than $B\left(1,900 \mathrm{~m}^{3} / \mathrm{h}\right)$ with 5.2 total air changes versus 2.1 in B. In the two cowsheds under study the amount of light (at least during winter) was not enough to perform breeding operations properly. These data could be also useful to add more information on beef traceability [9]. Continuous monitoring of microenvironmetal parameters could be a tool used by the breeders to improve cowshed management $[3,10]$.

\section{REFERENCES}

[1] CGIR Report Climatization of Animal Houses Report of Working group. Scottish Farm Building Investigation Unit. Craibstone, Aberdeen, Scotland 1984.

[2] Pedersen S, Sallvik K. CGIR $2^{\text {nd }}$ Report of Working Group on Climatization of Animal Houses; 1992.

[3] Pedersen S, Sallvik K. CGIR $4^{\text {th }}$ Report of Working Group on Climatization of Animal Houses. Heat and moisture production at animal and house levels 2002 .

[4] St-Pierre NR, Cobanov B, Schnitkey G, et al. Economic losses from heat stress by US livestock industries. J Dairy Sci 2003; 86(Suppl 13): E52-E77.

[5] Mader T. Managing feedlot heat stress. Published by University of Nebraska, Lincon Extension, Institute of Agriculture and Natural Resources 2000.

[6] UNI EN 12464 -1: 2004 (October 2004).

[7] Catalano P, Giametta F, Simoni A. A traceability system for the beef cattle farming channel. Proceedings of XVI CIGR World Congress - Agricultural Engineering for a Better World, Bonn (Germany), 3-7 September 2006; CDROM printed.

[8] Naas I, Campos S, Silva K. Comparison of manual and electronic traceability in swine production. CIGR Ejournal 2005; Vol. VII.

[9] Naas I. Applications of mechatronics to animal production. CIGR Ejournal 2002; Vol. IV.

[10] Müller HJ, Rom HB, Pedersen S. Comparison of methods of determination of ventilation flow in animal houses with different kinds of animals. proceedings of XVI CIGR world congress - agricultural engineering for a better world, Bonn (Germany), 3-7 September 2006; CDROM printed. 